in the liver via RNA, and will be discussed within the frame of current concepts of regulatory mechanisms in the synthesis of proteins. The possibility that these hormones regulate the formation of "clusters" of secondary gene products the expression of which may, or may not, be modified by substrates or dietary manipulations, will be considered.

1. Jervell, K. F. Acta Physiol. Scand. 50 (1960), suppl. 175, Abstr. p. 77.

2. Feigelson, P., Feigelson, M. and Greengard, O. 1st. Intern. Congr. Endocrinology, Abstr. Copenhagen 1960, p. 823.

3. Feigelson, M., Gross, P. R. and Feigelson, P. Biochim. Biophys. Acta 55 (1962) 495.

\section{Species Specificity of Amino Acyl RNA Synthetases from $E$. coli and Yeast}

\author{
Ulf Lagerkvist and
}

Joh a n W a l denströ m Dept. of Pediatrics, University of Gothenburg,
Gothenburg, Sweden

Berg et al. ${ }^{1}$ have reported that a methionyl RNA synthetase purified from yeast did only recognize $40 \%$ of the methionine sites on $E$. coli amino acid acceptor RNA (acc RNA) that are available to the homologous enzyme. Benzer and Weisblum ${ }^{2}$ using crude extracts of $E$. coli and yeast found striking differences in their ability to esterify non-homologous RNA depending on which amino acid was used. Rendi and Ochoa ${ }^{3}$ noted that crude $E$. coli extracts could not attach leucine to yeast RNA nor could yeast extracts esterify $E$. coli RNA with this amino acid. In view of these findings it seemed of considerable interest to make a systematic study of the species specificity of amino acyl RNA synthetases with purified enzyme preparations from $E$. coli and yeast.

As part of an attempt to extend previous investigations of the nucleotide sequences in acc RNA from $E$. $\operatorname{coli}^{4,5}$ to other microorganisms we have undertaken the purification of valyl-, leucyl-, and phenylalanyl RNA synthetases from yeast. The details of these procedures and of the purification of phenylalanyl RNA synthetase from $E$. coli will be reported elsewhere. Valyl-and leucyl-RNA synthetase from $E$. coli were prepared according to Bergmann et. al. ${ }^{6}$ A comparison of the properties of the yeast enzymes and their counterparts from $E$. coli gave the following results.

All of the yeast enzymes with the exception of the leucyl RNA synthetase were able to esterify $E$. coli RNA to approximately the same extent as tho $E$. coli enzymes as measured by the ruive of amino acid to RNA nucleotide. The maximal esterification of $E$. coli RNA obtained with yeast leucyl RNA synthetase was $60-70 \%$ of the available sites. On the other hand, of the $E$. coli enzymes only the valyl RNA synthetase could esterify yeast RNA to the same extent as the homologous enzyme. The leucyl- and phenylalanyl RNA synthetases did not attach amino acids to the non-homologous RNA to a measurable extent.

Comparisons of the reaction velocities catalyzed by the enzymes with homologous RNA as compared to non-homologous RNA revealed some interesting differences. In all the cases tested the velocities with the non-homologous RNA were considerably lower. The value obtained with yeast valyl RNA synthetase and $E$. coli RNA was $10-15 \%$ of the velocity with the "natural" substrate while the combinations yeast phenylalanyl RNA synthetase $E$. coli RNA and $E$. coli valyl RNA synthetase/ yeast RNA gave only $2-6 \%$ of the velocities with homologous RNA.

The results of analysis on the Hershey column ${ }^{7,8}$ of amino acyl RNA's synthesized with homologous and non-homologous enzymes will be discussed.

1. Berg, P., Bergmann, F. H., Ofengand, E. J. and Dieckmann, M. J. Biol. Chem. 236 (1961) 1726.

2. Benzer, S. and Weisblum, B. Proc. Natl. Acad. Sci. U.S. 47 (1961) 1149.

3. Rendi, R. and Ochoa, S. Science 133 (1961) 1367.

4. Lagerkvist, U. and Berg, P. J. Mol. Biol. 5 (1962) 139.

5. Berg, P., Lagerkvist, U. and Dieckmann, M. J. Mol. Biol. 5 (1962) 159.

6. Bergmann, F. H., Berg, P. and Dieckmann, M. J. Biol. Chem. 236 (1961) 1735.

7. Mandell, J. D. and Hershey, A. D. Anal. Biochem. 1 (1960) 66.

8. Sueoka, N. and Yamane, T. Proc. Natl. Acad. Sci. U.S. 48 (1962) 1454. 